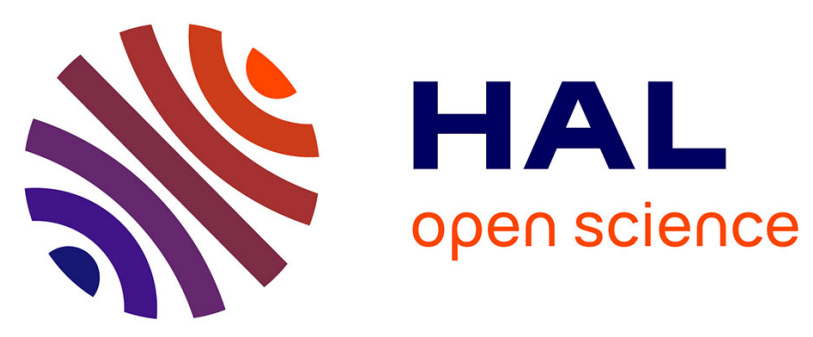

\title{
The 2008 map of consolidated rural areas in the Brazilian Legal Amazon state of Mato Grosso: Accuracy assessment and implications for the environmental regularization of rural properties
}

Damien Arvor, Vinicius Silgueiro, Gustavo Manzon Nunes, Jean Nabucet, André Pereira Dias

\section{To cite this version:}

Damien Arvor, Vinicius Silgueiro, Gustavo Manzon Nunes, Jean Nabucet, André Pereira Dias. The 2008 map of consolidated rural areas in the Brazilian Legal Amazon state of Mato Grosso: Accuracy assessment and implications for the environmental regularization of rural properties. Land Use Policy, 2021, 103, pp.105281. 10.1016/j.landusepol.2021.105281 . halshs-03507004

\section{HAL Id: halshs-03507004 \\ https://shs.hal.science/halshs-03507004}

Submitted on 4 Jan 2022

HAL is a multi-disciplinary open access archive for the deposit and dissemination of scientific research documents, whether they are published or not. The documents may come from teaching and research institutions in France or abroad, or from public or private research centers.
L'archive ouverte pluridisciplinaire HAL, est destinée au dépôt et à la diffusion de documents scientifiques de niveau recherche, publiés ou non, émanant des établissements d'enseignement et de recherche français ou étrangers, des laboratoires publics ou privés. 


\title{
The 2008 map of consolidated rural areas in the Brazilian Legal Amazon state of Mato Grosso: accuracy assessment and implications for the environmental regularization of rural properties
}

\begin{abstract}
Accurate land use mapping in the Amazon is crucial to support the implementation of environmental policies. The new Brazilian Forest Code published in 2012 defines a "consolidated rural area" (CRA) as an area within a rural property and occupied by humans prior to July 22, 2008. Environmental infractions that occurred before that date are granted amnesty and landowners are exempted from the obligation to restore the degraded areas. To assess the compliance of rural property owners with the environmental legislation, the Brazilian government created the Rural Environmental Registry (CAR), for mandatory electronic self-declaration of all rural private properties. The successful implementation of the CAR relies on the accurate mapping of CRA before the reference date of July 2008. The objective of the present paper is to assess the accuracy of the 2008 map of consolidated rural areas (CRA2008) that is the result of a fruitful collaboration between a non-governmental organization (NGO), a state administration and academic institutions. The CRA2008 map was produced by photo-interpretation of high resolution remote sensing images and validated after comparison with 90 aerial photographs. The validation metrics (overall accuracy $=0.926$, Kappa index $=0.851$ and F-score $=0.924)$ confirmed the reliability of the CRA2008 map. Most errors identified were due to imprecision at the edges between CRA and native vegetation because of different spatial resolutions of the CRA2008 and the aerial photographs. Consequently, the results were slightly lower (although still high; Kappa $=0.835$ ) in the Amazon biome where landscapes are more fragmented. Finally, in a context of severe criticisms expressed by national government leaders towards Brazilian research institutions and NGOs, our results clearly demonstrate the benefits of combining institutional efforts and of working in synergy to produce relevant
\end{abstract}


information with the aim of ensuring the implementation of public environmental policies and thereby improving land use sustainability in the Amazon.

Keywords: Brazilian Amazon, Rural Environmental Registry, Environmental governance, remote sensing

\section{Introduction}

Despite the rapid and significant reduction in deforestation in the Brazilian Amazon in the late 2000s (from 27,800 $\mathrm{km}^{2}$ in 2004 to 4,600 $\mathrm{km}^{2}$ in 2012), deforestation remains a hot topic as proven by the official statistics provided by the Brazilian National Institute for Space Research (INPE) pointing to a regular increase since $2012\left(7,900 \mathrm{~km}^{2}\right.$ in 2018) [1]. In this context, the federal government created the Environmental Regularization Program (PRA) to assess the compliance of private rural property owners with environmental legislation [2] and hence better control of land use dynamics in the Amazon. But to be efficient, the PRA depends on accurate mapping of open areas, named "consolidated rural areas" (CRA), in July 2008, the date of reference because the PRA has suspended all sanctions for environmental infractions that occurred before that date.

In the case of the Brazilian Amazon state of Mato Grosso, which is regularly in the spotlight because of its high deforestation rates $\left(1,685 \mathrm{~km}^{2}\right.$ in 2019, i.e. $17.26 \%$ of total deforestation in the Amazon), the non-governmental organization (NGO) Instituto Centro de Vida (ICV), in partnership with the Mato Grosso Secretary of State for Environment (SEMA-MT), was asked to map consolidated rural areas at a scale of 1: 25,000 based on visual interpretation of very high resolution remote sensing images. However, even though it has already been publicly released and is currently being used by the SEMA-MT to check private property owners are in compliance with the environmental legislation, the map has not yet been validated.

In line with the skepticism recently expressed by the Brazilian president regarding the legitimacy of official deforestation statistics for the Amazon [3] (exacerbated by the international media exposure of the multiplication of forest fires in the Brazilian Amazon in August 2019 and the resulting diplomatic incidents), the lack of validation statistics leaves room for criticism by stakeholders with diverging viewpoints and interests in territorial planning in the Amazon. 
As a consequence, there was an urgent need to assess the quality of the 2008 map of consolidated rural areas in Mato Grosso to limit the risks of misinterpretations, erroneous conclusions and controversial decisions while guaranteeing its use by SEMA-MT analysts to efficiently support the implementation of environmental public policies.

The objective of this paper is thus to present the 2008 official map of consolidated rural areas in Mato Grosso and to assess its quality. For this purpose, we brought together a complementary team including the map producers (the NGO Instituto Centro de Vida) and users (SEMA-MT) accompanied by academic institutions (Federal University of Mato Grosso and University of Rennes, in France) to implement the validation.

\section{Study area, Definitions and Data}

\subsection{Study area}

The state of Mato Grosso is located in the southern part of the Brazilian Amazon (Figure 1). It plays an important role in the Brazilian economy thanks to a very efficient agricultural sector specialized in the production of beef and important commodities including soybean, maize and cotton. The agribusiness began to emerge in Mato Grosso in the 1970s when the military government supported the colonization of the Amazon by private capital [4]. However, the expansion of agricultural land resulted in the direct or indirect clearing of large areas of Brazilian savannas (Cerrado) and Amazon forests

[5] and it became urgent to promote a new development model to decouple deforestation from agricultural production [6].

In this context, Mato Grosso is also at the forefront in the implementation of an environmental governance model to control deforestation and improve land use sustainability $[7,8,9,10]$. In the 2000s, major efforts by public administrations through the implementation of efficient command-and-control policies [11] and by the private sector through innovative market-oriented policies (i.e. Soy and Beef Moratorium [12, 13, 14]) led to a reduction of deforestation rates and a better compliance with the Brazilian Forest Code. This code is a major policy tool to control deforestation in Brazil that defines sub-areas in private rural properties including (1) the Permanently Protected Areas (PPAs), along water bodies and on sloping ground, and (2) Legal Reserve Areas (LRAs), corresponding to areas in which native vegetation is to be preserved, i.e., $80 \%$ of the entire property area in the Legal Amazon, $35 \%$ in Cerrado areas located in the Legal Amazon and 20\% elsewhere [4]. 
Although the Forest Code has long been recognized as indispensable to control deforestation, the way it was implemented has been severely criticized, which then led to its revision $[15,16]$. After years of debate, in 2012, a new Forest Code was implemented under the Federal Native Vegetation Protection Law $\mathrm{N}^{\circ} 12.651$ [17]. This new environmental legislation has long been the subject of controversy among experts, civil society and scientists for supporting the economic interests of the agribusiness sector that defends the full use of land to the detriment of the protection of the environmental function of rural properties, especially the preservation of native vegetation $[18,19]$. Indeed, the new Forest Code defines the concept of "consolidated rural area" as an area within a rural property and characterized by human occupation, i.e. buildings and/or agricultural activities, prior to July 22, 2008. This date corresponds to the publication of decree $\mathrm{N}^{\mathrm{o}} 6.514$ that defines environmental infractions and corresponding administrative sanctions [19]. The Environmental Regularization Program (PRA) then suspended all administrative fines for environmental infractions committed before that date, thus granting amnesty to those responsible for illegal deforestation and exempting landowners from the obligation to restore degraded areas, disregarding Decree $\mathrm{N}^{\circ} 3.179$ published in 1999 that defined sanctions for exploitation in Legal Reserve Areas. All illegal clearing and environmental damage that took place after July 22, 2008 have to be restored by the landowners according to decree $\mathrm{N}^{\mathrm{o}} 1.031$ published on June 2, 2017.

On the other hand, the new Forest Code also gave birth to the environmental regularization concept and led to the creation of the Rural Environmental Registry (CAR). The CAR is a mandatory registry for electronic self-declaration of all rural private properties in the Brazilian territory aimed at enabling assessment of their owners' compliance with the environmental legislation [2]. Landowners identified as not being in full compliance with the law shall be subject to sanctions and prevented from accessing services such as public agricultural loans [2].

In order to ensure the efficient implementation of the CAR, one of the major challenges consisted in mapping consolidated rural areas in Mato Grosso on the reference date (July 2008), essential information for the creation and analysis of the registries. But fine resolution mapping of these areas is difficult due to the huge siez of Mato Grosso state $\left(906,000 \mathrm{~km}^{2}\right)$, which includes three different biomes (Rainforest, Cerrado and Pantanal) and because the "consolidated rural areas" include many sub-classes (e.g. buildings, pastures, cropland) that make automatic remote sensing-based classification difficult. 


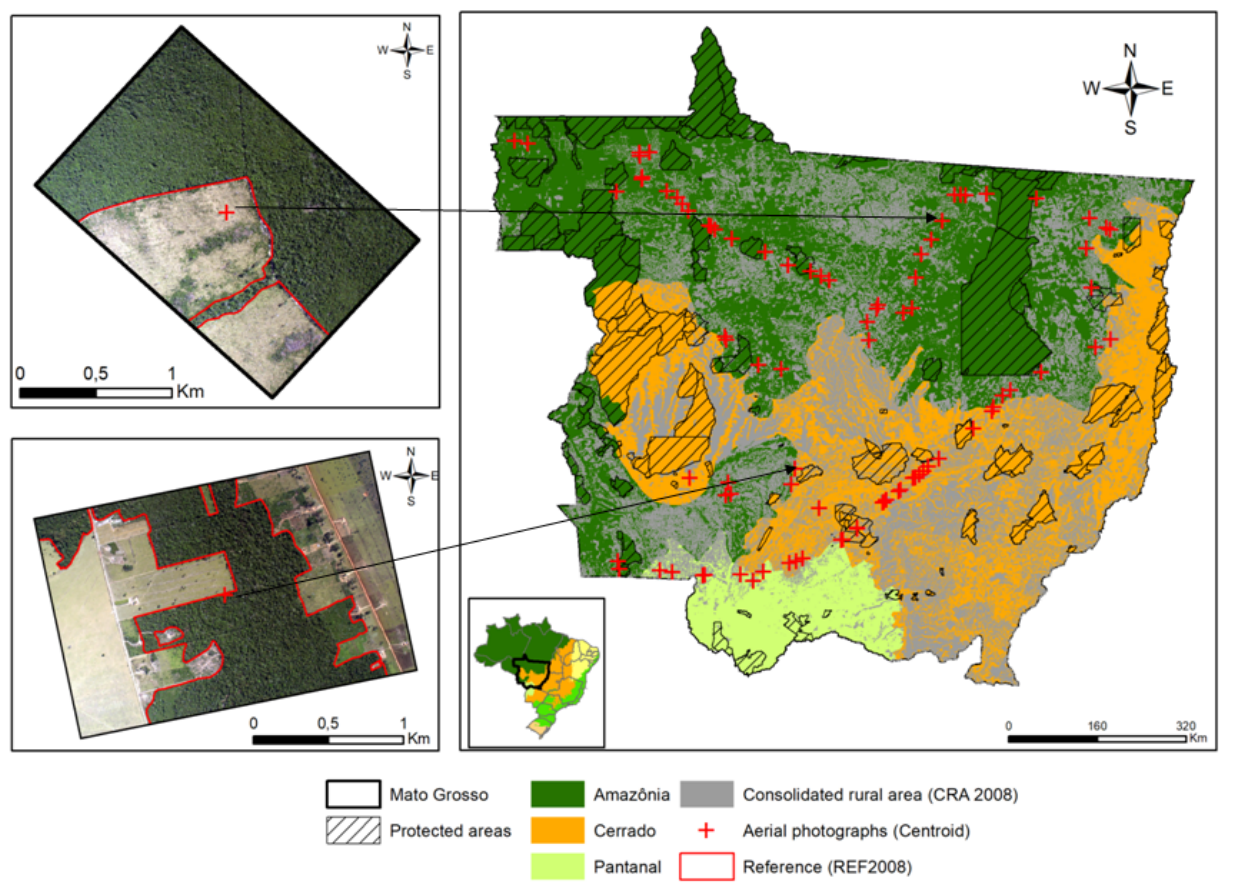

Figure 1: Location of the Brazilian Amazon state of Mato Grosso. Red crosses refer to the 90 aerial photographs used for validation. Two of these photographs are shown on the left side with corresponding reference mapping of consolidated rural areas. 


\subsection{Definition of consolidated rural areas}

The concept of consolidated rural area is defined in federal law $\mathrm{N}^{0} 12.651$ of May 25, 2012 as the area of a rural property under human occupation before July 22, 2008. In this definition of consolidated rural areas, the term rural property means urban areas are not included in the analysis. In addition, the term "human occupation" refers both to buildings and agricultural activities, including fallow land. Conversely, areas that were converted before July 22, 2008 and then abandoned or are undergoing of natural regeneration are not included in what is defined as consolidated rural areas. It is worth noting that distinguishing between a fallow and an abandoned area is based on duration, i.e. a fallow area remains a fallow for five years at most. Finally, degraded areas (e.g. burned areas), explored areas (e.g. timber logging) and natural pastures (especially present in the Pantanal and Cerrado biomes) are not included in what is defined as consolidated rural areas.

\subsection{Data}

Two datasets were used in this study: (1) the 2008 map of consolidated rural areas in Mato Grosso, hereafter CRA2008, and (2) 90 geometrically corrected aerial photographs with corresponding maps of consolidated rural areas for validation purposes, hereafter REF2008.

The CRA2008 map was produced between 2016 and 2017 by ICV and then reviewed by analysts from the department of Geoinformation and Environmental Monitoring Coordination (CGMA) at SEMA-MT. Mapping consolidated rural areas was a complex task that required taking into consideration both the land use observed circa 2008 and changes that occurred in the following years to confirm its continued use. For this reason, and with the aim of achieving the high degree of accuracy required for maps designed for the implementation of public policies, mapping was entirely based on the visual interpretation and digitization of satellite imagery, particularly SPOT5 images at $2.5 \mathrm{~m}$ spatial resolution acquired between 2007 and 2009. For areas covered by images acquired in 2009, Landsat-5 images (at $30 \mathrm{~m}$ spatial resolution) were used to confirm that cleared areas had already been in use in 2008. In addition, Landsat-8 and RapidEye (5 m spatial resolution) were used to check for any changes in land use in areas of interest, thereby confirming or rejecting the consolidated rural area status.

The methodological framework to map consolidated rural areas followed a technical note published by SEMA-MT on the interpretation of satellite images [20]. This technical note presents the main conceptual, legal and 
methodological characteristics that define a consolidated rural area, exemplifying how these areas can be observed in remote sensing images over the Amazon, Cerrado and Pantanal biomes. It thus seeks to standardize the interpretation of the class and its identification in satellite imagery in order to guide SEMA-MT analysts and environmental project developers [20]. As a result, a 1:25,000 continuous basis was obtained for the entire state of Mato Grosso where consolidated rural areas were estimated to account for 29.2 million ha in 2008, i.e. $32 \%$ of total area of the state (Figure 1). The data can be accessed at the following address cited in [21].

The REF2008 maps were produced using the same visual approach but using 90 aerial photographs at $60 \mathrm{~cm}$ spatial resolution. These photographs are archived on the SEMA-MT database and were acquired between July 11 and July 15, 2008 along a 3,686 km flight line originally designed to capture information about deforestation and forest degradation (Figure 1). A Nikon D200 camera with a 10.2 Mp resolution aboard an airplane was used. In this study, these images were considered as random samples to draw the REF2008 data for the purpose of validation. A total of 90 photographs were selected across the three biomes that comprise Mato Grosso, i.e. 57 photos taken in the Amazon, 26 in the Cerrado and 7 in the Pantanal biome (Figure 1). A total area of $294.09 \mathrm{~km}^{2}\left(3.26 \mathrm{~km}^{2}\right.$ in average per aerial photograph) was then used for validation, including $142.65 \mathrm{~km}^{2}$ mapped as consolidated rural area ( $48.5 \%$ of the validation area).

\section{Method used for the validation of the 2008 map of consolidated rural areas}

The CRA2008 map is intended to provide statistically accurate estimates. Given the size of Mato Grosso State (906,000 km2), identifying the potential errors to assess the spatial variability of the map's quality appears to be indispensable.

\subsection{Statistical analysis}

The validation procedure was based on regular sampling of 100 points in each aerial photograph (i.e. one point per $175 \mathrm{~m}$ approximately). The following information was then retrieved automatically for each sample point: 1) the classification labels in the CRA2008 and the REF2008 maps and 2) the type of biome. Based on this information, we computed confusion matrices 
and derived the statistical metrics commonly used in remote sensing applications: overall accuracy (OA), user's accuracy (UA), producer's accuracy (PA), the F-score and the Kappa index (K) [22]. These indices were calculated for each aerial photograph and then aggregated at biome level (e.g. Amazon, Cerrado and Pantanal) and for Mato Grosso as a whole.

\subsection{Error analysis}

We performed a qualitative analysis of erroneously classified polygons to qualify the sources of errors. In particular, we wanted to distinguish real classification errors by the photo-interpreters from precision errors resulting from data limitations mainly related to different acquisition dates and/or the different spatial resolutions between CRA2008 and REF2008 maps. In the following quantitative analysis, we then computed the distances between the wrongly classified points and the closest edge separating native vegetation from a consolidated rural area in the REF2008 data set. In this way, we analyzed the proportion of pixels that were wrongly classified due to uncertainties in the manual delineation of polygons in CRA2008 and REF2008 by different operators using different images $(2.5 \mathrm{~m}$ to $30 \mathrm{~m}$ for CRA2008 and $60 \mathrm{~cm}$ spatial resolution for REF2008). In addition, we extracted polygons of wrongly classified areas, i.e. the areas labelled as consolidated rural areas in REF2008 but not in CRA2008, and vice versa. We then computed their size and estimated the proportion of small polygons (here considered as less than 1 hectare as suggested by [23] and [24] for forest patches), considering that a high proportion of small polygons points to a high proportion of precision errors due to different spatial resolutions of CRA2008 and REF2008.

\subsection{Landscape analysis}

In the case of a large proportion of errors located at the edges between areas of consolidated rural areas and native vegetation, i.e. precision errors, one would expect the landscape structure to affect the validation metrics. Indeed, fragmented landscapes have longer edges and are thus more likely to be affected by precision errors. We thus calculated the accumulated edge length of polygons classified as consolidated rural areas in REF2008 (edges corresponding to the border of the photographs were discarded) for each

of the 90 aerial photographs in order to compute the correlation with the corresponding Kappa index. 


\section{Results}

\subsection{Statistical validation of the CRA2008 map}

Figure 2 shows some examples of aerial photographs and the corresponding mapping of consolidated rural areas as classified in the CRA2008 and REF2008 maps. They illustrate the overal satisfactory match between the CRA2008 map and the REF2008 dataset. This preliminary visual impression was confirmed statistically by the validation metrics (Table 1 ). The overall accuracy $(O A=0.926)$, Kappa index $(K=0.851)$ and F-score $(F-$ score $=0.924)$ for entire Mato Grosso were good and validate the high accuracy of the CRA2008 map. This accuracy was well balanced across biomes, with slightly higher values $(K=0.893)$ in the Pantanal and lower values $(K=0.835)$ in the Amazon. The F-scores were also very high $(>0.90)$ in all cases but the fact that producer accuracies were consistently higher than user accuracies indicated a slight tendency toward commission errors, i.e. overestimation of CRA areas. This is visually confirmed by the examples in Figure 2 where blue areas predominate over red areas.

\begin{tabular}{lcccccc} 
& UA & PA & F-score & OA & Kappa & N \\
\hline Aerial photograph & 0.920 & 0.969 & 0.924 & 0.945 & 0.873 & 90 \\
\hline Pantanal & 0.940 & 0.966 & 0.953 & 0.947 & 0.893 & 644 \\
Cerrado & 0.916 & 0.946 & 0.930 & 0.937 & 0.873 & 2,746 \\
Amazon & 0.891 & 0.946 & 0.918 & 0.917 & 0.835 & 5,570 \\
\hline Mato Grosso & 0.902 & 0.948 & 0.924 & 0.926 & 0.851 & 8,960
\end{tabular}

Table 1: Validation statistics of the CRA class at different spatial levels. UA: User Accuracy, PA: Producer Accuracy and OA: Overall Accuracy. For aerial photographs, values correspond to median values obtained for the $N=90$ photographs. For the other lines, the statistics were computed based on the number of validation points indicated in column $N$.

At the level of the aerial photographs, the median values across the 90 images are high for all validation metrics. Nonetheless, it is worth noting that four images have very low indices $(K a p p a<0.5)$ and thus deserve to be addressed in detail. These images are shown in Figure 3 to illustrate the different types of errors. In image $I D=8447$, there is no overlap between the consolidated rural areas in CRA2008 and REF2008 so the Kappa is null. The large red area refers to a vegetated area in which the presence of a house indicates human activities, thus justifying its classification as consolidated rural area in REF2008. However, this open area was not visible 

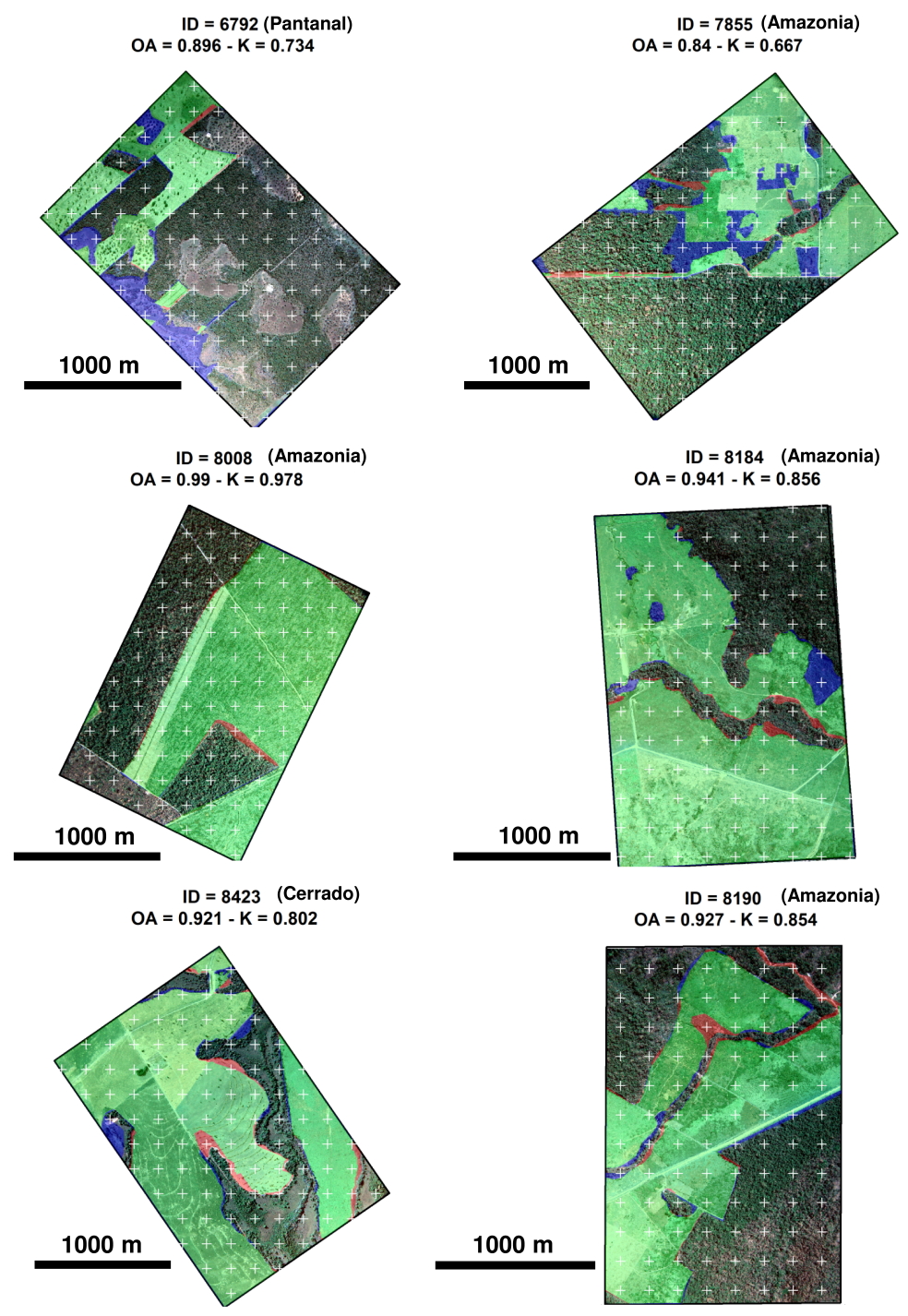

Figure 2: Examples of aerial photographs and mapping of consolidated rural areas (CRA) as classified in CRA2008 and REF2008. The green areas are classified as CRA in both products, thus representing correctly classified areas. The blue areas correspond to commission errors where areas are classified as consolidated rural area in CRA2008 but not in REF2008. The red areas identify omission errors when areas are classified as CRA in REF2008 but not in CRA2008. The white crosses represent the sample points used for validation. 
in the corresponding $2.5 \mathrm{~m}$ SPOT image used to produce the CRA2008 map and was consequently omitted. In image $I D=8301$, the error is due to the fact that the corresponding SPOT image was acquired in August 2007. At that date, the field was burned meaning the area had been cleared in 2007. However, it was not classified as consolidated rural area because it did not fit the definition of CRA (see section 2.2). In images $I D=7242$ and $I D=7909$, the CRA2008 map overestimated the consolidated rural areas by identifying large polygons (in blue) that were not visible in the reference aerial photographs. In the first case $(I D=7242)$, the large blue polygon corresponds to natural field areas in the Cerrado biome that were confused with consolidated rural areas in the $2.5 \mathrm{~m}$ SPOT image. In the second case $(I D=7909)$, the blue area refers to an area under regeneration in July 2007 that was misinterpreted as consolidated rural area by the photo-interpreter.

\subsection{Error analysis}

Although some real classification errors exist as illustrated in Figure 3, Figure 2 shows that most discrepancies between the two maps are actually located close to the edges between consolidated rural areas and native vegetation. Considering that the spatial resolution of a remote sensing image should be $1 / 2$ to $3 / 4$ the size of the smaller objects of interest in the scene [25], we can consider that wrongly classified points located less than $10 \mathrm{~m}$ from an edge are due to inaccuracy resulting from the fact that both CRA2008 and REF2008 maps were produced by visual interpretation but the images used had different spatial resolutions. Figure 4 presents the proportion of wrongly classified points depending on distance from the closest edge. The results show that $25 \%$ of erroneously classified points are located at less than $10 \mathrm{~m}$ from an edge (58\% of wrongly classified points are located less than 50 $\mathrm{m}$ from the closest edge and $90 \%$ less than $180 \mathrm{~m}$ from the closest edge). If these points $(<10 \mathrm{~m})$ were considered as correctly classified, then the validation metrics would increase significantly, OA would increase from 0.926 to 0.945 and Kappa from 0.851 to 0.890 . In addition, our analysis of wrongly classified polygons indicates that $95.46 \%$ of omitted polygons (in red areas in Figures 2 and 3) are less than 1 ha in size. Similarly, $90.03 \%$ of overestimated polygons (blue areas) are less than 1 ha; it should be recalled that 1 ha is considered to be the minimum mapping unit for forested areas [23]. 

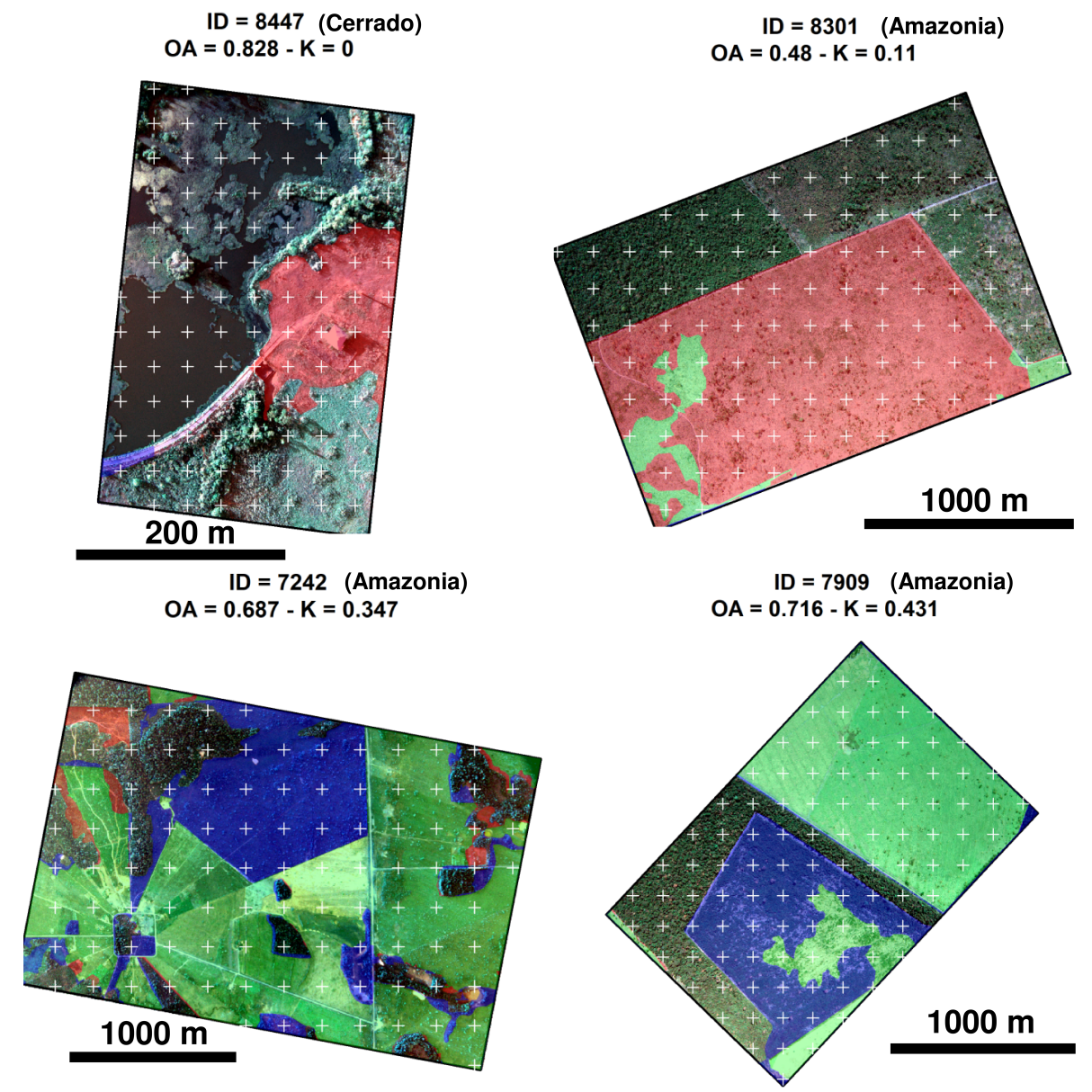

Figure 3: Examples of four aerial photographs with important classification errors. The two top photographs show cases of significant underestimation of consolidated rural areas (large red areas). The two bottom photographs show cases of overestimation (large blue areas). 


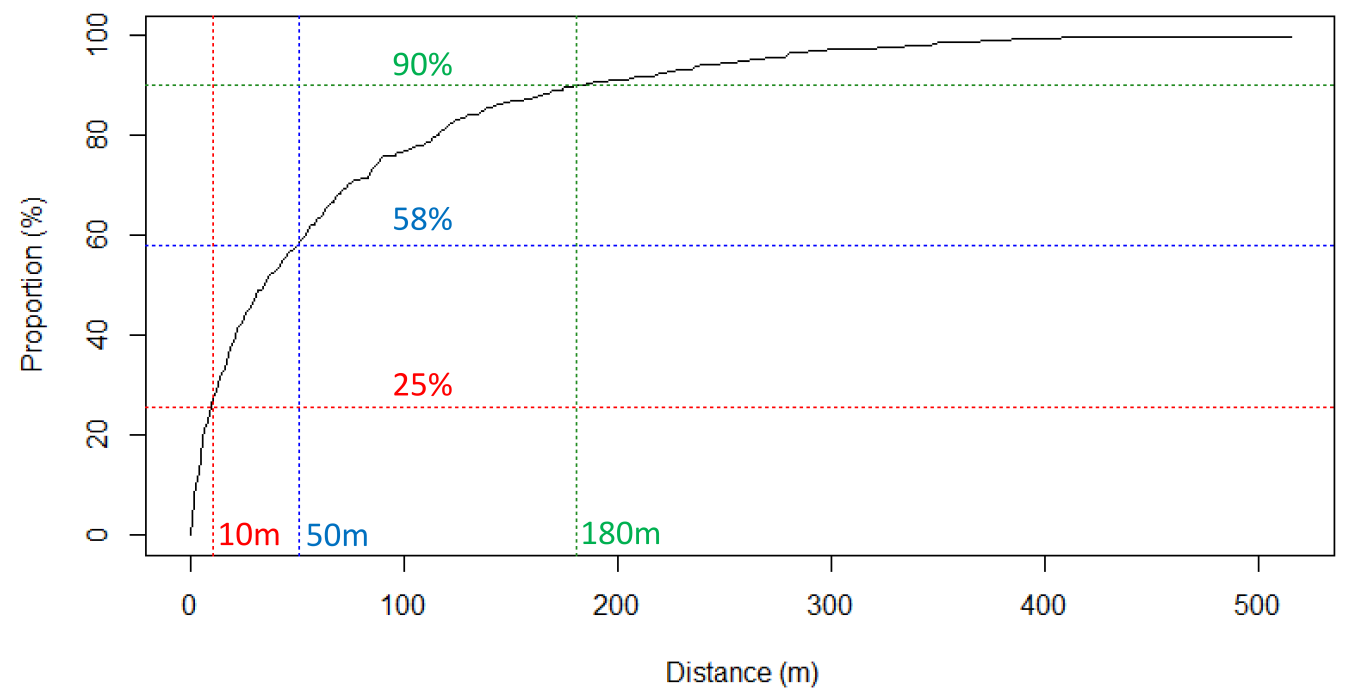

Figure 4: Proportion of wrongly classified sample points depending on the distance to the closest edge separating consolidated rural areas and native vegetation.

\subsection{Landscape analysis}

In order to check if the landscape structure explains the spatial variability of accuracy metrics, we plotted the edge length measured from REF2008 in each aerial photograph against the corresponding Kappa index (Figure 5). We removed the four images with very low Kappa values identified in Figure 3 because they are specific types of errors. Our results indicate a significant $(p-$ value $=1.659 e-06)$ relationship of $R^{2}=0.23$, evidence that the CRA2008 map is less reliable for fragmented landscapes. Considering that the mean edge length measured in the aerial photographs of Pantanal, Cerrado and Amazon biomes were 6,966 m, 9,641 m and 10,304 m, respectively, we conclude that the more fragmented landscapes observed in aerial photographs in the Amazon biome explain why the accuracy metrics are slightly lower (although still high) in this biome as shown in Table 1.

\section{Discussion}

Accurate mapping of consolidated rural areas in 2008 is very important to ensure the correct application of the CAR by state administrations of Mato Grosso, including SEMA-MT. The use of $2.5 \mathrm{~m}$ spatial resolution SPOT-5 images proved to be appropriate to achieve high levels of accuracy. Although 


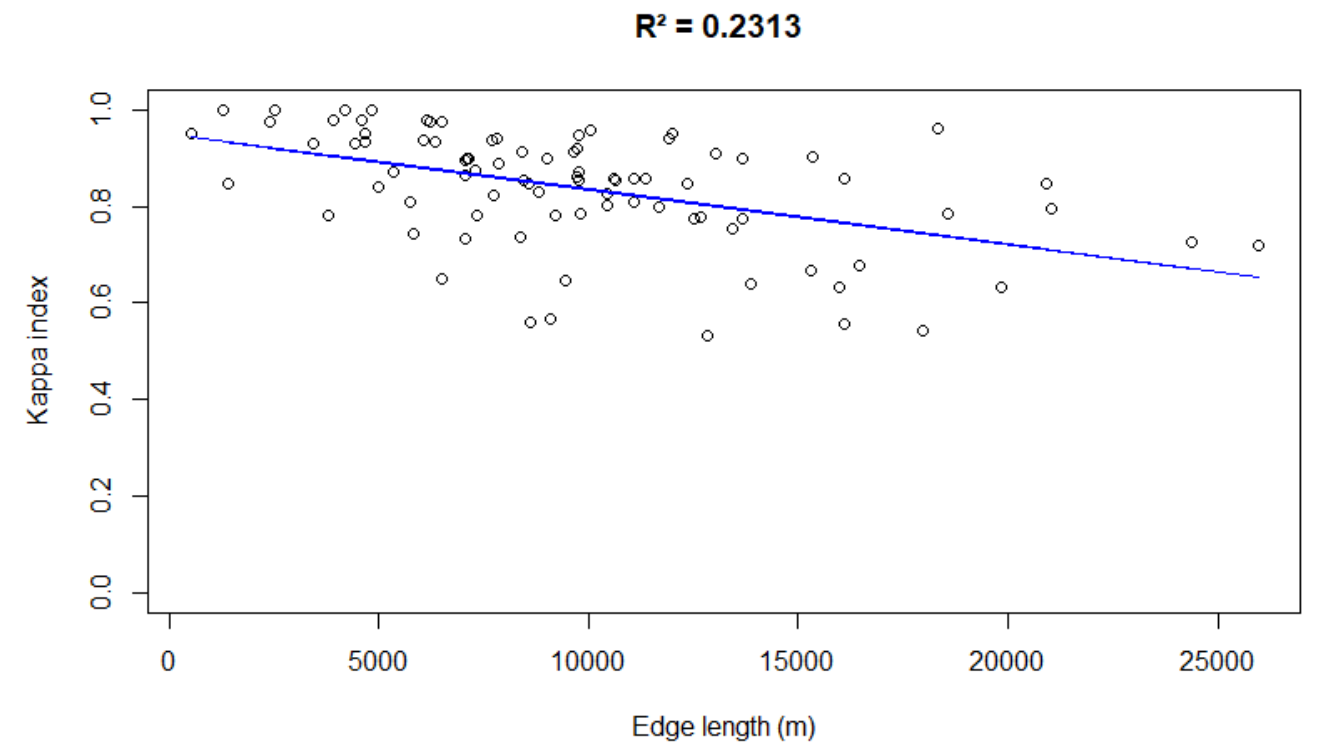

Figure 5: Relationship between edge length (in meters) of REF2008 and Kappa index measured on the corresponding aerial photographs.

image acquisition dates may differ from the reference date (July 2008) because it was technically impossible to obtain completely cloud-free coverage of Mato Grosso in this specific period, the procedure made it possible to confirm the status of consolidated rural areas using complementary Landsat-5 images acquired around July 2008.

The methodological approach based on visual interpretation was very effective given the accuracy revealed by the validation, and we consider it was the best way to proceed in order to produce a single map of a unique but complex land use class. In addition, visual interpretation is the method used by the technicians who design the environmental regularization projects in which SEMA-MT analysts are using the CRA2008 map as a reference. However, in the future, we may consider testing classifiers, e.g. support vector machine [26], random forest [27] or deep learning [28] tools, perhaps associated with Geographic Object-Based Image Analysis (GEOBIA) [29, 30].

Yet, the major concern to date regards the concrete use of the CRA2008 map for the implementation of present and future land use policies in the 
Southern Amazon. In this regard, it is worth noting that the CRA2008 map of consolidated rural areas is already being used by SEMA-MT technicians as a reference to implement the (1) Rural Environmental Registry (CAR) and (2) to issue Provisional Authorizations for the Rural Activity Operation (APF) [31]. Regarding the CAR, between August 23, 2018 and September $2019,5,502$ rural properties were analyzed, representing $9.3 \%$ of all registry entries uploaded by landowners and still waiting to be analyzed. Regarding APF, since October 2019, authorizations have started to be issued automatically based on the CRA2008 map. This authorization was introduced to allow rural producers to continue their agricultural activities (crop or livestock production) normally during the period SEMA-MT needs to adjust its licensing procedure to the changes in the new Brazilian Forest Code.

More importantly from our point-of-view, we wish to emphasize how the CRA2008 map contributes to the emergence of a new governance model in Mato Grosso. Indeed, while the search for compromise between competing development (e.g. incentives to private colonization) and environmental policies (e.g. Forest Code) has long been the rule and subject of disagreements between local stakeholders in Mato Grosso, significant efforts have been carried out during the last decades to promote integrated policies that would ensure both environmental preservation and socio-economic development [4]. The emergence of such integrated policies has been driven either by bottom-up strategies (such as the Sorriso Vivo project whose objective was to turn local rural properties from Sorriso municipality compliant with the environmental legislation by promoting forest restoration [32]) or by top-down market-oriented strategies (such as the Soy moratorium implemented to prohibit farmers who grew soy on deforested areas to sell their production [11]). At regional level, state administrations are also working in close collaboration with NGOs, private companies, farmers union, etc to promote a new governance model. As a major example, the Produce, Conserve, Include (PCI) program intends to increase agricultural efficiency while preserving native vegetation and restoring degraded areas [10]. Besides supporting all these initiatives, the CRA2008 map will also serve as a basis for the monitoring and quantification of regenerating and secondary forests (i.e. consolidated rural areas later observed as woody vegetation or forests), a fundamental information for the implementation of REDD (Reducing Emissions from Deforestation and forest Degradation) policies.

Yet, beyond the intentions, the concrete implementation of these laudable efforts is often called into question because the underlying motivations for 
changing the environmental governance model are still dubious, i.e. economic considerations or real environmental concerns [33]. In order to clarify that point, it is necessary to make accurate data publicly available and debatable in order to avoid future criticisms from stakeholders with diverging interests. In this regard, the production of the CRA2008 map is part of an innovative strategy since, differently from other deforestation maps and because it serves as a basis for regularization, landowners are entitled to challenge it, if they have doubts, or if errors are identified. A group of technicians with proven connections to agribusiness, indeed severely criticized the quality of the CRA2008 map. But, out of a total of 5,502 properties analyzed to date, SEMA-MT has only received 131 (2.3\%) official requests to check for inconsistencies in the interpretation of consolidated rural areas. Most errors were related to precision errors that may be particularly significant in the case of small properties. Obviously, there were also few classification errors due to confusion between consolidated and natural areas (e.g. cerrado and wetland) or degraded areas (such as burned areas or regenerating areas) in which case, manual editing is provided to improve the product. By fostering debate about the CRA2008 map, Mato Grosso state administrations hope to ensure its better acceptance and thus ease the environmental regularization process in Mato Grosso.

\section{Conclusion}

Here we have presented and assessed the quality of the 2008 map of consolidated rural areas in Mato Grosso, a reference map widely used by state administrations to deal with the demands for environmental regularization of rural properties. It serves as a basis for the implementation of public policy instruments that aim to ensure that agricultural commodities produced in Mato Grosso and exported worldwide have not been produced in recently deforested areas. This is a very important information since the environmental regularization of rural properties is necessary to ensure Brazil achieves its objectives to reduce greenhouse gas emissions as it may also impact future international economic agreements (e.g. the European Union-Mercosur Free Trade Agreement [34, 35]). Nonetheless, the efficiency of such policies to contain deforestation remains to be proven. For example, Azevedo et al. [36] produced evidence that registered properties originally showed lower deforestation rates than non-registered ones, but that these differences tended to diminish over time. 
At a time when the political debate about the development models to be promoted in the Amazon is the center of attention in the global media, the validation of spatial information data appears essential to limit controversial analyses and this paper is a contribution in that direction. Yet, its importance is also maximized by recent criticisms directed at non-governmental organizations and research institutions, since this study is the result of a fruitful collaboration between a Brazilian non-governmental organization, a state administration and academic institutions. It thus provides evidence for the interest of combining institutional efforts and working in synergy to produce relevant information with the final objective of ensuring the implementation of environmental public policies and consequently improving land use sustainability in the Amazon.

\section{Acknowledgements}

The authors wish to thank (1) the Climate and Land Use Alliance (CLUA), (2) the State Government of Mato Grosso, (3) the French National Centre for Space Studies (CNES) which funded the CASTAFIOR project (grant agreement 168591), (4) the European Union which funded the H2020-MSCARISE-2015 ODYSSEA project (Project Reference: 691053) and (5) the French National Centre for Scientific research which funded the SCOLTEL International Emerging Action.

\section{References}

[1] INPE, Taxas de desmatamento na Amazônia (2019). URL: http: //terrabrasilis.dpi.inpe.br/app/dashboard/deforestation/ biomes/legal_amazon/rates.

[2] I. Roitman, L. C. G. Vieira, T. K. B. Jacobson, M. M. da Cunha Bustamante, N. J. S. Marcondes, K. Cury, L. S. Estevam, R. J. da Costa Ribeiro, V. Ribeiro, M. C. Stabile, R. J. de Miranda Filho, M. L. Avila, Rural Environmental Registry: An innovative model for land-use and environmental policies, Land Use Policy 76 (2018) 95102. URL: https://doi.org/10.1016/j.landusepol.2018.04.037. doi:10.1016/j.landusepol.2018.04.037.

[3] H. Escobar, Brazilian president attacks deforestation data, Science 365 (2019) 419-419. URL: https://doi.org/10.1126/science. 365. 6452.419. doi:10.1126/science.365.6452.419. 
[4] D. Arvor, M. Daugeard, I. Tritsch, N. A. D. Mello-Thery, H. Thery, V. Dubreuil, Combining socioeconomic development with environmental governance in the Brazilian Amazon: the Mato Grosso agricultural frontier at a tipping point, Environment, Development and Sustainability 20 (2016) 1-22. URL: https://doi.org/10.1007/s10668-016-9889-1. doi:10.1007/s10668-016-9889-1.

[5] F. Gollnow, L. de Barros Viana Hissa, P. Rufin, T. Lakes, Propertylevel direct and indirect deforestation for soybean production in the Amazon region of Mato Grosso, Brazil, Land Use Policy 78 (2018) 377-385. URL: https://doi.org/10.1016/j.landusepol.2018.07. 010. doi:10.1016/j.landusepol.2018.07.010.

[6] M. N. Macedo, R. S. DeFries, D. C. Morton, C. M. Stickler, G. L. Galford, Y. E. Shimabukuro, Decoupling of deforestation and soy production in the southern Amazon during the late 2000s, Proceedings of the National Academy of Sciences 109 (2012) 1341-1346. URL: https:// doi.org/10.1073/pnas.1111374109. doi:10.1073/pnas.1111374109.

[7] G. L. Galford, B. Soares-Filho, C. E. P. Cerri, Prospects for land-use sustainability on the agricultural frontier of the brazilian amazon, Philosophical Transactions of the Royal Society B: Biological Sciences 368 (2013) 20120171. URL: https://doi.org/10.1098/rstb.2012.0171. doi:10.1098/rstb.2012.0171.

[8] I. Tritsch, D. Arvor, Transition in environmental governance in the Brazilian Amazon: emergence of a new pattern of socio-economic development and deforestation, Land Use Policy 59 (2016) 446455. URL: https://doi.org/10.1016/j.landusepol.2016.09.018. doi:10.1016/j.landusepol.2016.09.018.

[9] D. Arvor, I. Tritsch, C. Barcellos, N. Jégou, V. Dubreuil, Land use sustainability on the south-eastern amazon agricultural frontier: Recent progress and the challenges ahead, Applied Geography 80 (2017) 8697. URL: https://doi.org/10.1016/j.apgeog.2017.02.003. doi:10. 1016/j.apgeog. 2017.02.003.

[10] C. Milhorance, M. Bursztyn, Emerging hybrid governance to foster lowemission rural development in the Amazon frontier, Land Use Policy 75 
(2018) 11-20. URL: https://doi.org/10.1016/j.landusepol.2018. 03.029. doi:10.1016/j. landusepol.2018.03.029.

[11] D. Nepstad, D. McGrath, C. Stickler, A. Alencar, A. Azevedo, B. Swette, T. Bezerra, M. DiGiano, J. Shimada, R. S. da Motta, E. Armijo, L. Castello, P. Brando, M. C. Hansen, M. McGrath-Horn, O. Carvalho, L. Hess, Slowing Amazon deforestation through public policy and interventions in beef and soy supply chains, Science 344 (2014) 1118-1123. URL: https://doi.org/10.1126/science. 1248525. doi:10.1126/science. 1248525.

[12] H. K. Gibbs, L. Rausch, J. Munger, I. Schelly, D. C. Morton, P. Noojipady, B. Soares-Filho, P. Barreto, L. Micol, N. F. Walker, Brazils Soy Moratorium, Science 347 (2015) 377-378. URL: https://doi.org/10. 1126/science.aaa0181. doi:10.1126/science. aaa0181.

[13] C. Silva, M. Lima, Soy Moratorium in Mato Grosso: Deforestation undermines the agreement, Land Use Policy 71 (2018) 540542. URL: https://doi.org/10.1016/j.landusepol.2017.11.011. doi:10.1016/j.landusepol.2017.11.011.

[14] J. H. Kastens, J. C. Brown, A. C. Coutinho, C. R. Bishop, J. C. D. M. Esquerdo, Soy moratorium impacts on soybean and deforestation dynamics in Mato Grosso, brazil, PLOS ONE 12 (2017) e0176168. URL: https://doi.org/10.1371/journal . pone. 0176168. doi:10.1371/journal pone. 0176168.

[15] C. M. Stickler, D. C. Nepstad, A. A. Azevedo, D. G. McGrath, Defending public interests in private lands: compliance, costs and potential environmental consequences of the brazilian forest code in Mato Grosso, Philosophical Transactions of the Royal Society B: Biological Sciences 368 (2013) 20120160. URL: https://doi.org/10.1098/rstb. 2012.0160. doi:10.1098/rstb.2012.0160.

[16] J. Tollefson, Brazil set to cut forest protection, Nature 485 (2012) 19-19. URL: https://doi .org/10.1038/485019a. doi:10.1038/485019a.

[17] R. H. Taniwaki, Y. A. Forte, G. O. Silva, P. H. Brancalion, C. V. Cogueto, S. Filoso, S. F. Ferraz, The Native Vegetation Protection Law 
of Brazil and the challenge for first-order stream conservation, Perspectives in Ecology and Conservation 16 (2018) 49-53. URL: https: //doi. org/10.1016/j.pecon. 2017.08.007. doi:10.1016/j.pecon. 2017.08 . 007.

[18] B. Soares-Filho, R. Rajao, M. Macedo, A. Carneiro, W. Costa, M. Coe, H. Rodrigues, A. Alencar, Cracking brazils forest code, Science 344 (2014) 363-364. URL: https://doi.org/10.1126/science.1246663. doi:10.1126/science.1246663.

[19] D. D. Felippe, F. Trentini, O conceito de área rural consolidada no código florestal de 2012: principais controvérsias, Revista de Direito Agrário e Agroambiental 4 (2018) 77. URL: https://doi. org/10.26668/indexlawjournals/2526-0081/2018.v4i1.4260. doi:10.26668/indexlawjournals/2526-0081/2018.v4i1.4260.

[20] SEMA-MT, Satellite image interpretation methodology for the definition of consolidated areas in Mato Grosso state, Technical Report Technical note N001/2017/CGMA/SRMA/SEMA-MT, 2017. URL: http://sema.mt.gov.br/attachments/article/4420/Nota\% 20Tecnica $\% 20$ n $\% 2001 \% 20-\% 202017 \% 20-\% 20$ Uso $\% 20$ Consolidado.pdf.

[21] ICV, Map of consolidated rural areas - CRA2008, 2019. URL: http://geo.sema.mt.gov.br/geoserver/semamt/ows?service= WFS\&version $=1$.0.0\&request $=$ GetFeature\&typeName=semamt : usoconsolidado-07-02-2017\&outputFormat=SHAPE-ZIP, accessed: 2020-03-09.

[22] R. G. Congalton, A review of assessing the accuracy of classifications of remotely sensed data, Remote Sensing of Environment 37 (1991) 3546. URL: https://doi .org/10.1016/0034-4257 (91)90048-b. doi:10 . 1016/0034-4257(91)90048-b.

[23] UNFCCC, Report of the Conference of the Parties serving as the meeting of the Parties to the Kyoto Protocol on its first session, held at Montreal from 28 November to 10 December 2005. Part Two: Action taken by the Conference of the Parties serving as the meeting of the Parties to the Kyoto Protocol at its first session., Technical Report FCCC/KP/CMP/2005/8/Add.3, 2006. URL: https : //unfccc. int/resource/docs/2005/cmp1/eng/08a03.pdf. 
[24] C. Sannier, R. E. McRoberts, L.-V. Fichet, Suitability of Global Forest Change data to report forest cover estimates at national level in Gabon, Remote Sensing of Environment 173 (2016) 326-338. URL: https:// doi.org/10.1016/j.rse.2015.10.032. doi:10.1016/j.rse.2015.10. 032 .

[25] D. J. Marceau, P. J. Howarth, D. J. Gratton, Remote sensing and the measurement of geographical entities in a forested environment. 1. the scale and spatial aggregation problem, Remote Sensing of Environment 49 (1994) 93-104. URL: https://doi.org/10.1016/00344257 (94)90046-9. doi:10.1016/0034-4257 (94)90046-9.

[26] G. Mountrakis, J. Im, C. Ogole, Support vector machines in remote sensing: A review, ISPRS Journal of Photogrammetry and Remote Sensing 66 (2011) 247 - 259. URL: http://www. sciencedirect.com/science/ article/pii/S0924271610001140. doi:https://doi.org/10.1016/j. isprsjprs.2010.11.001.

[27] M. Belgiu, L. Dragut, Random forest in remote sensing: A review of applications and future directions, ISPRS Journal of Photogrammetry and Remote Sensing 114 (2016) 24 - 31. URL: http://www. sciencedirect.com/science/article/pii/S0924271616000265. doi:https://doi.org/10.1016/j.isprsjprs.2016.01.011.

[28] X. X. Zhu, D. Tuia, L. Mou, G. Xia, L. Zhang, F. Xu, F. Fraundorfer, Deep learning in remote sensing: a review, CoRR abs/1710.03959 (2017). URL: http://arxiv.org/abs/1710.03959. arXiv: 1710.03959.

[29] T. Blaschke, Object based image analysis for remote sensing, ISPRS Journal of Photogrammetry and Remote Sensing 65 (2010) 2-16. URL: https://doi.org/10.1016/j.isprsjprs.2009.06.004. doi:10.1016/ j.isprsjprs.2009.06.004.

[30] T. Blaschke, G. J. Hay, M. Kelly, S. Lang, P. Hofmann, E. Addink, R. Q. Feitosa, F. van der Meer, H. van der Werff, F. van Coillie, D. Tiede, Geographic object-based image analysis - towards a new paradigm, ISPRS Journal of Photogrammetry and Remote Sensing 87 (2014) 180-191. URL: https://doi.org/10.1016/j . isprsjprs .2013.09.014. doi:10. 1016/j.isprsjprs. 2013.09.014. 
[31] SEMA-MT, SEMA emite automaticamente autorização provisória para áreas de uso consolidado, 2019. URL: http: //www.mt.gov.br/-/13162268-sema-emite-automaticamenteautorizacao-provisoria-para-areas-de-uso-consolidado, accessed: 2020-02-24.

[32] D. Arvor, V. Dubreuil, P. M. del Villar, C. M. Ferreira, M. S. P. Meirelles, Développement, crises et adaptation des territoires du soja au mato grosso: lexemple de sorriso, Confins (2009). URL: https: //doi.org/10.4000/confins.5934. doi:10.4000/confins.5934.

[33] N. A. de Mello-Théry, E. de Lima Caldas, B. M. Funatsu, D. Arvor, V. Dubreuil, Climate change and public policies in the brazilian amazon state of mato grosso: Perceptions and challenges, Sustainability 12 (2020) 5093. URL: https://doi.org/10.3390/su12125093. doi:10.3390/su12125093.

[34] S. Afionis, L. C. Stringer, The environment as a strategic priority in the european union-brazil partnership: is the EU behaving as a normative power or soft imperialist?, International Environmental Agreements: Politics, Law and Economics 14 (2013) 47-64. URL: https://doi .org/ 10.1007/s10784-013-9232-3. doi:10.1007/s10784-013-9232-3.

[35] L. Kehoe, T. N. dos Reis, P. Meyfroidt, S. Bager, R. Seppelt, T. Kuemmerle, E. Berenguer, M. Clark, K. F. Davis, E. K. zu Ermgassen, K. N. Farrell, C. Friis, H. Haberl, T. Kastner, K. L. Murtough, U. M. Persson, A. Romero-Muñoz, C. O'Connell, V. V. Schäfer, M. Virah-Sawmy, Y. le Polain de Waroux, J. Kiesecker, Inclusion, transparency, and enforcement: How the EU-mercosur trade agreement fails the sustainability test, One Earth 3 (2020) 268-272. URL: https://doi.org/10. 1016/j.oneear.2020.08.013. doi:10.1016/j. oneear.2020.08.013.

[36] A. A. Azevedo, R. Rajão, M. A. Costa, M. C. C. Stabile, M. N. Macedo, T. N. P. dos Reis, A. Alencar, B. S. Soares-Filho, R. Pacheco, Limits of brazil's forest code as a means to end illegal deforestation, Proceedings of the National Academy of Sciences 114 (2017) 76537658. URL: https://doi.org/10.1073/pnas.1604768114. doi:10. 1073/pnas. 1604768114. 